\title{
Confluencia de tradiciones culturales en las llanuras del caribe colombiano. El caso de los sitios arqueológicos La Floresta y Macumba en Tolú Viejo (departamento de Sucre)
}

\author{
Aceneth Serna Ramírez \\ Corporación Antropológica para la Investigación \\ < aceneth.serna@gmail.com >
}

\begin{abstract}
RESUMEN
Este artículo ha sido escrito a partir de los hallazgos arqueológicos de los sitios La Floresta y Macumba (municipio de Tolú Viejo, departamento de Sucre, Colombia) y el rastreo de las principales fuentes documentales tanto crónicas del siglo XVI, como proyectos arqueológicos precedentes. Pretende mostrar la confluencia de dos tradiciones culturales: los grupos Zenú y Malibú localizados en las tierras bajas costeras de la Región Caribe colombiana. Esta región con sus grandes ríos como el Magdalena, Sinú, San Jorge, Nechí y Cauca ha jugado, sin duda, un papel importante en las dinámicas sociales del territorio colombiano. Ha sido escenario de las principales rutas de poblamiento, vías naturales de comunicación y los ecosistemas asociados a estos han servido de fuentes alimentarias para los pobladores tanto prehispánicos como actuales.
\end{abstract}

PALABRAS CLAVE: Tradiciones culturales, orfebrería, túmulos funerarios, urnas, agro-alfareros, cacicazgos.

\section{Confluence of cultural traditions in the plains of the colombian caribbean. The case of the archaeological sites La Floresta and Macumba in Tolú Viejo (Department of Sucre)}

\section{ABSTRACT}

This article has been written from the archaeological findings of the sites La Floresta and Macumba (municipality of Tolú Viejo, department of Sucre, Colombia) and the tracking of the main documentary sources both chronicles of the sixteenth century and previous archaeological projects. It aims to show the confluence of two cultural traditions: the Zenú and Malibú groups located in the coastal lowlands of the Colombian Caribbean Region. This region, with its great rivers such as Magdalena, Sinú, San Jorge, Nechí and Cauca, has undoubtedly played an important role in the social dynamics of the Colombian territory. It has been the scene of the main settlement routes, natural communication routes and the ecosystems associated with them, they have served as food sources for both prehispanic and current inhabitants.

KEYWORD: Cultural traditions, goldsmiths, burial mounds, urns, agro-potters, chiefdoms. 


\section{Introducción}

$\square$ n el territorio colombiano la riqueza cultural de la Costa caribe es innegable, pues ha sido hogar de comunidades indígenas desde la península de La Guajira, donde actualmente vive el pueblo Wayuú, pasando por el macizo montañoso de la Sierra Nevada de Santa Marta, habitada por los pueblos Kogui, Arhuaco, Kankuamo y Wiwa. Los Chimilas se asentaron en gran parte del valle del río Magdalena, mientras que los departamentos de Córdoba y Sucre han sido territorio de los Zenú, los Malibú y los Emberá Katío (Lozada, 2013).

En los sitios arqueológicos La Floresta y Macumba localizados en el departamento de Sucre, uno de los ocho que conforman la región del Caribe colombiano, se obtuvieron evidencias arqueológicas que pudieron ser relacionadas con los grupos indígenas Zenú y Malibú. Dichos sitios fueron identificados durante las labores de Monitoreo Arqueológico ${ }^{1}$ en la ejecución de las obras de construcción del Gasoducto Loop San Mateo-Mamonal de propiedad de la empresa PROMIGAS S.A., especialmente en los trabajos del zanjado, en la zona rural del Municipio de Tolú Viejo. El primero en las coordenadas E: 848627 y N1533683 y el segundo en las coordenadas E: 850610 y N154436.

La ubicación de los grupos Zenú y Malibú se da gracias a las fuentes etnohistóricas relatadas por cronistas en el siglo XVI y por los trabajos arqueológicos que las corroboran. (Plazas et al., 1981 y 1993; Archila, 1993; Falchetti, 1979, 1995a, 1995b, 1996, 1999 y 2010). Tanto los Zenú como los Malibú fueron grupos indígenas agro-alfareros, sedentarios, localizados en cercanías a grandes ríos como Sinú, San Jorge, Cauca, Nechí y Magdalena.

Las culturas Zenú y Malibú fueron hábiles ceramistas. $\mathrm{Al}$ interior de sus estructuras sociales ésta actividad estaba reservada para un gremio especializado que dominaba los conocimientos acerca de las arcillas, los tipos de desgrasantes para las mismas (fragmentos molidos, arena fina y gruesa, cerámica molida, fibras vegetales, conchas marinas trituradas), aditivos que se

1 Una de las fases de los programas de Arqueología Preventiva en Colombia. Al respecto, el Instituto Colombiano de Antropología e Historia ICANH (ente regulador del patrimonio cultural colombiano), considera que estos programas se desarrollan mediante las fases de Diagnóstico, Reconocimiento, Prospección y Formulación del Plan de Manejo Arqueológico, Ejecución del Plan de Manejo Arqueológico, Monitoreo, Excavaciones, Salvamento, Definición de la tenencia de bienes arqueológicos y Divulgación de los resultados (ICANH; 2010). debían usar para darle mejor plasticidad y condiciones apropiadas para soportar las temperaturas del proceso de cocción, así como las técnicas de modelado.

Los valles de los ríos Sinú, San Jorge, Cauca y Nechí fueron los territorios donde se asentaron los Zenú, desde las cercanías del río Sinú hasta el río Magdalena y, por el sur, hasta el departamento de Antioquia (Rodríguez, 1999). Se encontraban divididos en tres provincias Finzenú, Panzenú y Zenúfana. La relación entre ellas era de complementariedad económica y religiosa pero no una confederación política. El excedente del oro Zenúfana se enviaba hacia el norte en donde se obtenía sal. Así mismo, los de la costa fabricaban hamacas destinadas al intercambio (Oleoducto de Colombia S.A. et al., 1994).

Estaban estructurados en cacicazgos. El cacicazgo Zenúfana era el principal por encima del Finzenú y Panzenú, cargo que podía ser ejercido tanto por hombres como por mujeres quienes tenían un control en todos los aspectos de la sociedad. Esta última la conformaban la gente del pueblo, personas con trabajos especializados como orfebres sacerdotes o mohanes, y los caciques (Rodríguez, 1999).

Eran grupos orfebres: «Desde 1533, año en que se fundó Cartagena de Indias, los conquistadores supieron de las enormes riquezas de los entierros indígenas del río Sinú, desde allí organizaron expediciones y se inició una larga historia de profanación de túmulos funerarios» (Plazas y Falchetti, 1981: 21).

las casas eran de paredes altas redondeadas de otras construcciones que abrumaron a los españoles por la semejanza con sus propias viviendas. Encontraron también edificaciones mayores para sus ceremonias. El testimonio cuenta que en una hallaron 24 ídolos de madera vestidos con planchas de oro que tenían sobre los hombros una gruesa vara en que estaba colgada una hamaca donde los nativos dejaban el oro que traían como ofrenda (Plazas y Falchetti, 1981: 21).

Los Zenú fueron reconocidos por su complejo manejo del paisaje: la creación de un sistema hidráulico prehispánico de canales artificiales que cubrían una extensión de 500.000 hectáreas de tierras cenagosas. La esencia de estos canales era controlar las aguas y aprovechar la fertilidad de la tierra abonada por las inundaciones, lo cual les permitió acceder a mejores recursos agrícolas y pesqueros. Estas obras de ingeniería prehispánica se adaptaban a funciones agroecológicas 

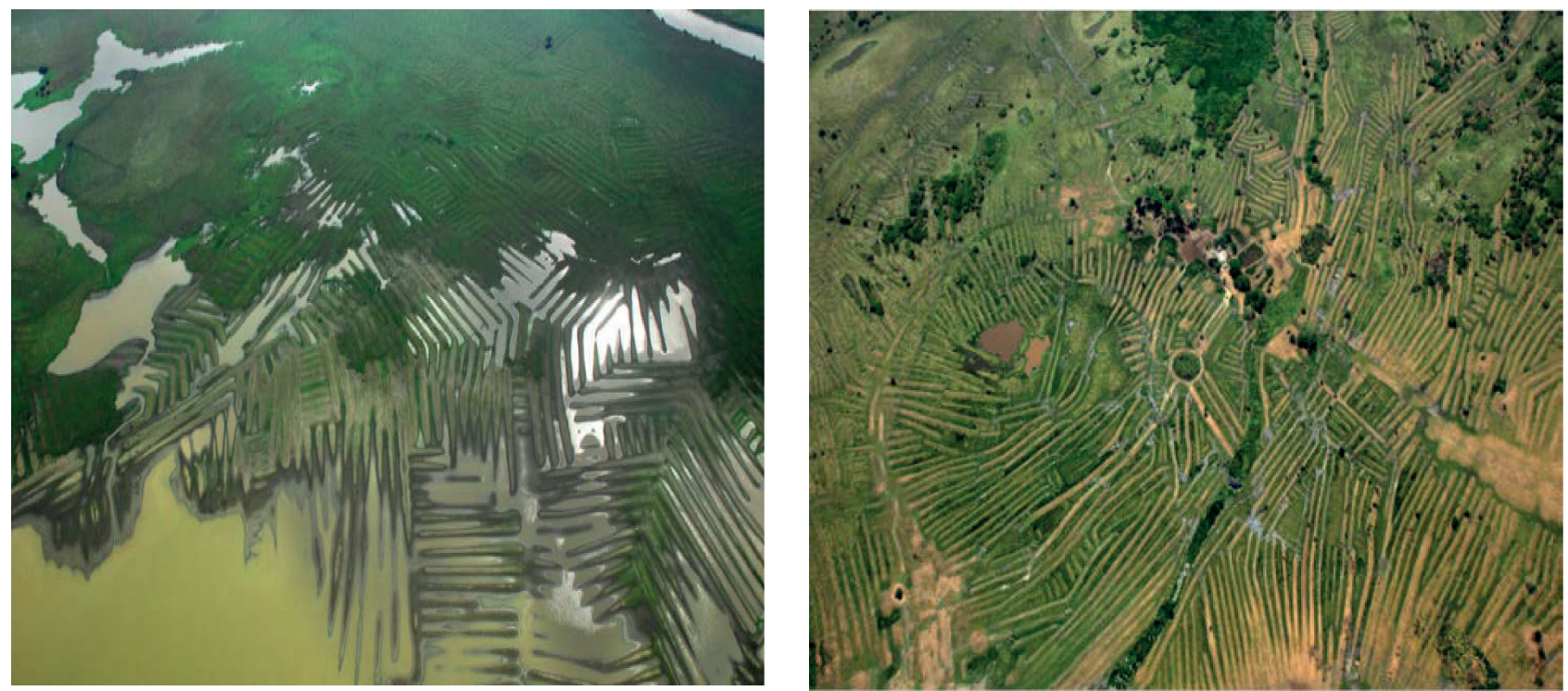

Canales y camellones de riego. Fotos aéreas de Sebastián Schrimpff (Foto Rudolf) 2008, (c) Banco de la República, Colombia.

como cultivos y a condiciones topográficas como meandros, concibiéndose canales en forma de pescado, de Y, de estrella, de cuadriculas ajedrezadas y abanicos (Plazas y Falchetti, 1981; Ortiz et al., 2006).

Los Malibú, por su parte,

Se adaptaron a climas secos y con el aporte de una economía mixta basada en la pesca, la horticultura de la yuca, combinada con el cultivo del maíz, tuvieron una dispersión geográfica desde las riberas del río Magdalena y las orillas de las lagunas cercanas entre Tamalameque y Tenerife, incluyendo la depresión Momposina; se extendieron hacia el norte, alcanzando la región de Cartagena, donde se denominaron como Mocaná (Bernal y Orjuela 1992, en Choperena, 2015: 19).

Existen registros que demuestran que los grupos Zenú llegaron a las sabanas de Sucre y a las estribaciones sur de las Montañas de María, el contacto se estableció con grupos de ascendencia lingüística Caribe nombrados como los Malibú, de quienes se sabe que estaban divididos lingüísticamente en tres tribus que hacían parte de la misma familia: Los Malibú propiamente dichos, ubicados en las riberas del río Magdalena; los Pacabuy o Sompallón, habitantes de las lagunas; y los Mocaná, localizados en los sectores aledaños al litoral Caribe en el Canal del Dique y algunas islas cercanas a la costa (Escalante, 1955; Reichel-Dolmatoff, 1991).

La diferencia más notoria entre los Zenú y los Malibú es, quizás, la forma en que enterraban a sus muertos. Los Zenú lo hacían en túmulos funerarios que hacen parte hoy del paisaje rural de la región Caribe. Los entierros de los Malibú, por el contrario, se localizaron directamente sobre el suelo o en urnas funerarias en las que se depositaron los restos óseos del difunto, sin ningún tipo de alteración visible, es decir, no construyeron túmulos funerarios.

Cuando se mueren los malebúes hacen de un palo cavado como manera de ataúd y su tapa y todo si es indio principal o si tiene parientes que lo hagan, y hacen un hoyo grande y muy hondo, de más de un estado, cuanto se alcanza con la mano y allí los entierran y a la redonda de sí le ponen muchas múcuras de chicha y ollas de maíz....y también le ponen allí una hacha y un machete y un arco y flechas. Y si tiene cuentas o algún oro en las narices, caracolíes de oro, orejeras o canutillos de oro, con todo esto solían enterrar dentro de sus buhíos.... los caribes dicen que no los enterraban hasta que el cuerpo estaba podrido....y que lo cargaban en los hombros encima de un tablón que hacían a manera de ataúd y lo llevaban por todo el pueblo con toda la gente llorando....y después de esto hacían dos hoyos hondos en el buhío del propio cacique y le descarnaban todo, que le dejan los huesos blancos y la carne hechan en uno de los hoyos y los huesos en el otro o en una múcura, que es una olla guinde, y les cubren de tierra (Briones, 1983: Cap. XIV. 165).

Dentro de los rituales de los Zenú, debe destacarse las ceremonias de muerte, conocida como el festival funerario: 
Primero se celebraban las vísperas y se preparaba todo lo indispensable, entre lo cual la chicha era indispensable. En la noche se hacía una procesión acuática, en la que el cortejo fúnebre desfilaba por el río. En embarcaciones adornadas iban los mohones (médicos brujos) y los gobernantes, cuidadosamente ataviados y con cocuyos sobre las cabezas. Concluía la ceremonia con el entierro de un túmulo artificial cuya altura dependía de la calidad del muerto. El cadáver se colocaba con la cabeza hacia y luego todos pisaban la tierra sobre la fosa y se bailaba sin parar; la cacica y el mohán dirigían el entierro y ordenaban repartir la comida y la bebida. Al acabarse la chicha, se sembraba una ceiba sobre el montículo (www. sahaguncordoba.com _en línea con mi pueblo los zenú).

Por su parte, Oviedo y Valdés, exponen: «En unos pueblos se entierran en atahudes, é métenles de comer é de beber a los difuntos, quando los sepultaban, é una escudilla é una taca, con que coma é beba el muerto, é su ropa assi como una manta é un ceñidor, é su oro é sus joyas é su arco é flechas; é las mujeres lo mesmo, y en lugar de arco ponerle su rueca é huso, con que hilan el algodón» (Oviedo y Valdés, 1535).

En cuanto a confluencia de estas tradiciones culturales en investigaciones de Falchetti (1995) y Choperena (2012), se reportaron evidencias de registro arqueológico de los indígenas que habitaron el norte del actual departamento de Sucre pasado el siglo XII hasta después de la colonización. Se trata de piezas de orfebrería Zenú tardía halladas al interior de urnas funerarias, asociadas con la Tradición cerámica Incisa Alisada, referenciada para ambos grupos indígenas los Zenú y los Malibú (Falchetti, 1995a; Choperena, 2015). Así mismo y, como se expondrá en las siguientes líneas, en el sitio arqueológico La Floresta es posible hallar al interior de urnas funerarias piezas de orfebrería con características de ambas tradiciones culturales. Y si bien el lugar de enterramiento presenta características de los Zenú, la decoración de algunas vasijas cerámicas es típica de la cultura Malibú.

Antes de dar inicio a la discusión, es oportuno hacer un reconocimiento al interés y apoyo recibido por la empresa Promigas S.A, quien subsidió la investigación, en particular al ingeniero Silvestre Campo Carey. El proyecto se realizó con los arqueólogos Enrique Campo Mier, Fabio Ortiz Sánchez, Luz Marina Mora González, Oscar Moscoso Marín, Lenin Campo Morales, Jesús Pérez Fuentes, Oscar Julián Moscoso
Marín y Carlos Orozco Rúa. El análisis de restos óseos lo realizó Edixon Quiñones Reyes, el estudio paleoambiental estuvo a cargo de Carlos A. Monsalve $\mathrm{M}$, la asesoría en geo-arqueología fue realizada por Carlos López Castaño, Martha Cecilia Cano Echeverri y José Alfonso Realpe. Finalmente, los auxiliares de investigación fueron Ilianis Sánchez Bolaños, Alba Araque Campo, Wilmar Córdoba Díaz, Andrea Chía Góngora, Andrés Restrepo Campo y Mery Luz Arroyave Crespo. A todos, gracias.

\section{Evidencias arqueológicas de los grupos Zenú y Malibú en el Caribe colombiano}

El sector donde se localizan los sitios arqueológicos La Floresta y Macumba es de la mayor importancia en lo referente con los procesos de poblamiento prehispánico y las rutas de comunicación a través de la historia. Es un lugar estratégico de las tierras bajas del Caribe colombiano, entre la costa Atlántica (sector Golfo de Morrosquillo-Cartagena) y los Montes de María. Allí se han reportado distintas evidencias de ocupaciones en varios periodos. En este sentido, los datos de la región del Caribe son la base para la interpretación del pasado prehispánico colombiano, en particular, con el inicio de las primeras prácticas hortícolas y comienzos de la vida sedentaria, pasando por la adopción de la alfarería, la agricultura y los grandes desarrollos regionales (cacicazgos), incluso, algunas manifestaciones de sociedades pre-estatales (Reichel Dolmatoff, 1982 y 1986; Rodríguez, 1988; Langebaek, 1997; Langebaek y Dever, 2000 y Oyuela, 1995).

La Floresta y Macumba se encuentran en el departamento de Sucre, al noroccidente de Colombia, en las llanuras del Caribe, aproximadamente entre los $10^{\circ} 08^{\prime} 03$ " y $08^{\circ} 16^{\prime} 46$ ” de latitud N y los 74032'35" de longitud W. Dicho departamento puede ser dividido en 5 subregiones. Una importante subregión corresponde a los Montes de María, específicamente los municipios de Sincelejo, Ovejas y Morroa. Su paisaje es montańoso, con predominio de bosque seco tropical. Otra subregión corresponde a la de Sabanas, en la que la obra atraviesa los municipios de San Pedro, Sincé, San Juan de Betulia y Corozal. Esta corresponde a una zona de transición entre el territorio montañoso de los Montes de María y la depresión de los ríos Cauca y San Jorge. Predomina un paisaje de ondulaciones de colinas que van desde los 70 a los $185 \mathrm{msnm}$. Otra 
región diferenciada es la de Morrosquillo con los municipios de Tolú Viejo y San Onofre. Esta última región, donde se localizaron los sitios La Floresta y Macumba, se encuentra en la zona costera del golfo del mismo nombre y se caracteriza por la predominancia de bosques secos.

En los últimos ańos se vienen aportando nuevos datos a las problemáticas de poblamiento y de contextos funerarios de la región los que, sin lugar a dudas, sirvieron de referente para la realización del presente estudio arqueológico. Deben mencionarse, entre otras, las investigaciones de Chacín, Romero, Rey y Choperena.

Entre los municipios de San Pedro y Córdoba la arqueóloga Regina Chacin (1999) identificó un sitio de habitación y enterramiento secundario en urnas funerarias de un grupo agro alfarero, en el cual se encontraron acumulaciones estratigráficas de depósitos materiales que representan una extensa área de vivienda con posibles huellas de poste de antiguas estructuras, un cementerio, acumulaciones de fragmentos cerámicos (posible basurero), áreas de fogones y acumulaciones de ceniza. Los materiales arqueológicos se relacionaron con los grupos humanos que habitaron el sur de los Montes de María en épocas tardías, es decir en el siglo xv (Chacin, 1999).

Posteriormente, en el municipio de Buena Vista, la misma autora hacia el 2005 (Chacin, 2005), identifica en las cimas de lomas y colinas en los sectores de Canutal, Canutalito, Paloquemao, Moralito y Guepaje, cinco sitios arqueológicos con presencia de alfarería, restos óseos y herramientas de piedra, además de ser reportada por los habitantes del sector la presencia de piezas de orfebrería al interior de urnas funerarias. Considera Chacín que la muestra cerámica al igual que la orfebrería, podría pertenecer a grupos agroalfareros asociados posiblemente con los Malibú y los Zenú (Chacin, 2005).

Entre el 2006 y 2007 Yuri Romero hace varios trabajos en el municipio de San Pedro en los que identifica material cerámico y lítico característico de la región. El primero está relacionado con el material de Zambrano en Bolívar y Tamalameque en Cesar (Romero, 2006, 2007. En Choperena, 2015).

Dos años después, Fabio Rey realiza una exploración arqueológica en lo Montes de María, en los municipios de Ovejas y San Pedro. Los yacimientos identificados durante este trabajo - en total 11 - tienen en común el estar ubicados cerca de fuentes de agua, en algunos casos arroyos o ciénagas, en zonas medianamente altas con pocas posibilidades de presentar inundaciones. Se hallaron evidencias arqueológicas como: cerámicas, material lítico y restos óseos. La muestra cerámica está conformada por 57 fragmentos que fueron asociados con el tipo cerámico Tenerife y al Tipo Malambo. En cuanto al material lítico se reporta el hallazgo de 19 artefactos tallados en chert negro y amarillo. Los restos óseos corresponden a fragmentos de tibias y otros indeterminados en muy mal estado de conservación (Rey, 2009; en Choperena, 2015).

El trabajo más reciente lo realiza Choperena hacia el 2012, quien adelanta excavaciones en el sitio San Felipe en Los Palmitos. Se trata de un cementerio indígena donde se identificaron tres tipos de tumbas o contextos funerarios. Para establecer la diferencia entre ellos se utilizó como criterio la forma en que se encontraban depositados los restos óseos y la disposición del ajuar funerario. A saber: a) Con los restos óseos al interior de la urna funeraria, b) en urna funeraria compartida y c) sin urna funeraria. Así mismo se recuperaron 38 piezas de orfebrería, cinco de ellas provenientes de excavación y el resto de decomiso ${ }^{2}$. Las provenientes de excavación fueron encontradas junto a los restos óseos y una ocarina al interior de la urna del Contexto Funerario $\mathrm{N}^{\circ} 2$, cuyo ajuar externo fue el más numeroso entre los contextos excavados. Las cinco piezas son: un colgante Darién, dos orejeras en falsa filigrana, una argolla delgada y una nariguera en forma de $\mathrm{N}$ en oro de alta ley, material que fue correlacionado con la orfebrería de la tradición cultural Zenú y Malibú (Choperena, 2015).

\section{La Floresta y Macumba: lugares de vivienda de vivos y muertos}

El sitio arqueológico La Floresta se encuentra en la vereda del mismo nombre perteneciente al municipio de Tolú Viejo, departamento de Sucre. Presenta una fisiografía compuesta de superficies planas que van desde el litoral Caribe en el Golfo de Morrosquillo hasta las estribaciones de los Montes de María. El paisaje general corresponde a colinas de pie de monte, el cual se ha labrado a partir de rocas sedimentarias.

2 Toda vez que la investigación se realizó luego de un proceso de guaquería por parte de los campesinos de la zona, por lo que un buen porcentaje del material fue decomisado por las autoridades en cual permitió contextualizar las evidencias recuperadas durante la excavación. 
La subunidad es una cim a de colina de lomeríos interconectados de piedemonte. El lote donde se halla este sitio tiene una vegetación de pastos, árboles pequeños y rastrojo bajo y ha sido utilizado para actividades de pastoreo de ganado de cría y engorde cebú y romo-sinuano. El sector, en general, ha tenido por más de 30 años vocación agrícola, destacándose entre otros los cultivos de ñame, yuca, arroz, maíz, algodón y sorgo.

Presenta La Floresta una extensión de casi una hectárea y se ubica sobre una pequeña cima de no más de 210 m.s.n.m. Espacios elevados como el descrito han sido utilizados reiteradamente por los grupos humanos del sector para construir las viviendas de vivos y muertos, buscando estar alejado de las zonas cenagosas, muy comunes en el Caribe colombiano.

La Floresta, de acuerdo con las evidencias recuperadas, es un sitio de enterramientos secundarios, pues los restos óseos fueron dispuestos al interior de las urnas funerarias. El ajuar funerario fue tanto externo, ya que se depositaron elementos por fuera de la urna $\mathrm{y}$ asociados al mismo evento, como interno pues se depositaron piezas al interior de esta. Por medio del análisis de C14, se obtuvo una fecha de $230 \pm 30 \mathrm{BP}$. (Edad radiocarbono 2 sigma calibrated result cal AD 1650-1695 (cal BP 300-255). 95\% probability cal AD 1725-1805 (cal BP 225-145) (Laboratorio Number Beta-456779 CF1. Beta Analytic, 2017).

Los principales vestigios obtenidos fueron los siguientes: urnas funerarias con predominio de formas subglobulares, ovoides y semiovoides, con y sin ajuares funerarios, tanto internos como externos; entre los cuales se destacan pequeñas vasijas, copas, budares, manos de moler, siete elementos orfebres, cuentas de collar en cerámica y cuarzo, volantes de huso y una cabeza de bastón en cerámica. Además de herramientas líticas como hachas pulidas medianas y manos de moler encontradas en el fondo de algunas de las urnas, en los costados o en la base del piso.

En términos de clasificación la cerámica se relacionó con dos tipologías que pudieron ser correlacionadas con la Tradición Cerámica de los Zenú (existen, sin embargo, particularidades en algunas de las pequeñas vasijas en cuanto a la decoración con rasgos de los grupos Malibú). La primera corresponde a una cerámica rojiza con atributos que van desde una variación de colores Rojo [HUE 2.5 YR 4/6] y Rojo naranja [HUE 5 YR 6/8] en la pasta, el acabado de la superficie es lisa, de núcleo compacto con características de cocción gris o negra y una variación de espesor tanto mediano como grueso; el desgrasante es de mineral, arena fina y en ciertos casos se observan gránulos de arena gruesos, además de la presencia de cuarzo, mica y feldespato. En esta tipología la decoración está conformada por incisiones, excisiones, punteados e impresiones dactilares junto a una impresión en forma de pequeños triángulos.

La segunda tipología es una cerámica negra con desgrasante mineral de arena fina con gránulos medianos. Se observa una disminución de la presencia de cuarzo con una casi nula presencia de mica y feldespato; con acabado de superficie lisa y variación de espesores medianos como delgados con colores Negro [HUE 7.5YR 2.5/1], Gris [GLEY 1 5/] y Gris Oscuro [HUE 7.5YR 4/1] en la pasta. Para esta tipología se tiene un predominio de los motivos decorativos lineales $\mathrm{y}$ algunos fragmentos con aplicaciones zoomorfas $\mathrm{y}$ antropomorfas.

La presencia de restos óseos y dentales al interior de las urnas fue una constante. El material óseo se encontraba en mal estado de conservación, pese al sumo cuidado con el que fueron excavados. Su proceso de deterioro se evidenció aún más durante la fase de laboratorio. Su tratamiento consistió en el lavado de cada uno de los elementos, secado a temperatura ambiente y pegado con UHU cuando fue posible reconstruir, al menos parcialmente, algún material.

Para el caso de los dientes, se estudiaron las características morfológicas de cada una de las estructuras a fin de identificar las piezas presentes (incisivos, caninos, premolares, molares) y determinar su posición anatómica (superior, inferior, izquierdo, derecho); posteriormente, utilizando una base de cera dental se reconstruyeron las arcadas dentales de cada uno de los individuos, para proceder al inventario de las mismas siguiendo la nomenclatura dentaria internacional.

Las evidencias corresponden a 30 individuos; de los cuales 16 son adultos, 5 juveniles y 9 infantiles. Igualmente, se observan múltiples individuos contenidos en una sola urna; destacándose la urna 1 con cuatro individuos, de los cuales dos son adultos, uno juvenil y uno infantil; la urna 2 con un adulto, un juvenil y un infantil; la urna 3 con tres adultos y un joven; la urna 4 con tres adultos; la urna 5 con dos adultos; la urna 20 con un adulto y un juvenil y la urna 22 con un adulto y un niño. Lo anterior estaría indicando que se trata de entierros secundarios en 
urnas funerarias tanto individuales como compartidas, muy comunes en la región.

Según el registro en los sedimentos de las muestras de suelo del sitio arqueológico predominaron los indicadores de intervención o manejo de recursos tipo leñosos los que tal vez fueron aprovechados con fines energéticos como, por ejemplo: para el sustento y protección, entre otros. También se evidenció la presencia de hifas y esporas de hongos relacionados, tal vez, con materia orgánica y del aprovechamiento de algunas herbáceas no leñosas como pastos, y, por los fitolitos encontrados, es posible que entre estos pastos se encuentre el maíz.

En la muestra La Floresta-4, se encontraron algunas pequeñas semillas circulares que aparentemente tienen afinidad con algunas hierbas arbustivas tipo Eudicotiledónea (Plantas vasculares con flor) y otra semilla indeterminada, que ha sido observada en otros sitios de Colombia (Valle del Cauca) y en el Ecuador (comunicación personal Carlos A. Monsalve M.).

El conjunto de la metalurgia lo componen cuatro cascabeles o sonajeros, una nariguera en forma de $\mathrm{N}$, dos narigueras (orejeras?) ${ }^{3}$ macizas en forma de anillo y una orejera semicircular. Los objetos fueron elaborados mediante las técnicas propias de la cultura Zenú como el martillado y el fundido, utilizando aleaciones de oro y cobre (tumbaga), la que ha tenido influencias de otras culturas entre las que se encuentran los Malibú. Están elaboradas, las primeras, por hilos fundidos que forman diseños en zigzag colocados en franjas separadas entre sí por hilos paralelos simples o torcidos; dos hilos torcidos colocados juntos frecuentemente forman un diseño en forma de trenza. Los sonajeros o cascabeles son reconocidos por ser usados en conjunto. $\mathrm{Al}$ parecer se elaboraron para armar collares y son generalmente pequeños, huecos y cerrados excepto por una ranura en su zona inferior. En su interior tienen una piedra pequeńa y redonda o una esfera de cobre.

Acorde con Falchetti (1995: 32), la orfebrería de la tradición cultural Zenú ha sido clasificada en cinco conjuntos: Zenú temprano, el Grupo de Planeta Rica, el Grupo de Ayapel, el Grupo San Jorge-Cauca y el Grupo de la Serranía de San Jacinto. Este último es el más tardío y el que mejor se relaciona con las piezas del sitio La Floresta (Falchetti, 1995: 25-35).

3 Que por la posibilidad de diversos usos en diferentes partes del cuerpo no se puede establecer con precisión si son unas u otras.
El Grupo de la Serranía de San Jacinto: Muestra la influencia de la orfebrería Zenú, pero una orientación tecnológica diferente - con un particular énfasis en el uso del cobre- e influencias diversas, lo definen como un conjunto único que se prolongó hasta épocas tardías, aún después de la conquista española. Su contexto de hallazgo es diferente al de los grupos anteriores. Piezas relacionadas con esta orfebrería aparecen también en el bajo Magdalena y formaron parte del inmerso intercambio de tumbaga en esas regiones, en el cual cumplieron un papel fundamental Los Malibúes del bajo Magdalena, orfebres y comerciantes de río. En la zona oriental de las llanuras del Caribe, la confluencia de dos tradiciones culturales - la de los Zenúes y la de los Malibúes - tiende a reflejarse en la producción metalúrgica (Falchetti, 1995: 32).

Así las cosas, la técnica de elaboración de narigueras semicirculares y narigueras en forma de $\mathrm{N}$ es propia de los Zenú, pero el manejo de tumbaga es propio de los Malibú: puede considerarse, entonces, una confluencia de tradiciones culturales entre ellos. Ahora bien, el contexto funerario del sitio, si bien tiene características de los Zenú en cuanto a la forma de enterramiento, en la disposición de algunos ajuares y en la decoración de algunas vasijas cerámicas también tiene características de los Malibú.

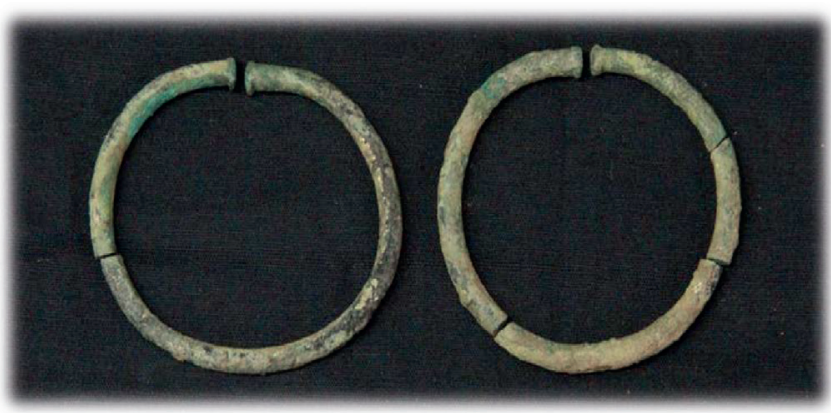

Narigueras-Orejeras halladas en La Floresta

Existen referencias en crónicas del siglo XVI y en documentos del uso de "aros de oro" que podían ser usados como orejeras alrededor de todo el circuito de la oreja. En el caso de los Malibúes del Bajo Magdalena que «traían también en las orejas unos arillos de oro, toda la oreja de arriba abajo» (Falchetti, 1995: 141).

El sitio arqueológico Macumba se localiza en la vereda Cienaguita del municipio de Tolú Viejo, departamento de Sucre, en medio de un sistema de colinas bajas, sobre la margen derecha de un afluente episódico del arroyo Cal. Dicha vereda se extiende sobre 
la llanura aluvial de convergencia hacia el occidente. Dista unos 100 metros del cańo Macumba, del cual toma su nombre.

Macumba se ubica sobre una terraza que es drenada por un sistema que se proyecta desde las laderas de los Montes de María hasta el Golfo de Morrosquillo. El eje de esta red de drenaje en el área del sector es el arroyo Cal.

Corresponde a un sitio de enterramiento secundario pues los restos óseos fueron dispuestos al interior de las urnas funerarias tanto individuales como compartidas. El ajuar funerario fue tanto externo, pues se depositaron elementos por fuera de la urna y asociados al mismo evento, como interno, pues se depositaron piezas al interior de esta. De acuerdo con la datación establecida según los resultados de C14 para el sitio: $1380 \pm 30$ BP (Edad radiocarbono 2 sigma calibrated result cal AD 650-690 - (cal BP 1300-1260). 95\% probability cal AD 735-765 (cal BP 1215-1185) (Laboratory number Beta-456780 CM1). (Beta Analytic, 2017).

Considerando que el caño ha cambiado de curso recientemente, se observa que se ha dado en este lugar un proceso de formación de un sitio arqueológico vinculado a la sedimentación de los materiales que traen las lluvias. Los pobladores prehispánicos aprovecharon para sus enterramientos sobre esta terraza la existencia de suelos sueltos que se encuentran en un relativo equilibrio por ser la terraza plana y elevada. Los suelos han perdido temporalmente los materiales finos por procesos de erosión laminar. Se puede observar que las urnas están depositadas sobre unos espacios arenosos y fueron cubiertas con sedimentos probablemente de la misma excavación; luego, sobre todo este material se desarrolló un incipiente suelo el cual tiene características de un entisol.

Desde el punto de vista ecológico, en el sitio Macumba predominaron condiciones de clima seco, inferencia que surge por la escasa presencia de indicadores de humedad y de agua. Así, se podría establecer que probablemente entre los siglos VII y VIII de nuestra era, tal vez se presentaron condiciones de clima seco en el sitio y entorno de Macumba. Más exactamente entre los 650 y los 765 A D calibrados, rango de cronologías obtenida con 2 sigma de probabilidad (95\%)- (Beta Analytic, 2017).

Por ejemplo, Castro y Gómez indican que en clima cálido los contenidos de M.O. (materia orgánica) menores a $1.5 \%$ son bajos, entre 1.5 y $3 \%$ son medios y mayores a $3 \%$ son altos; y que contenidos de $\mathrm{P}$

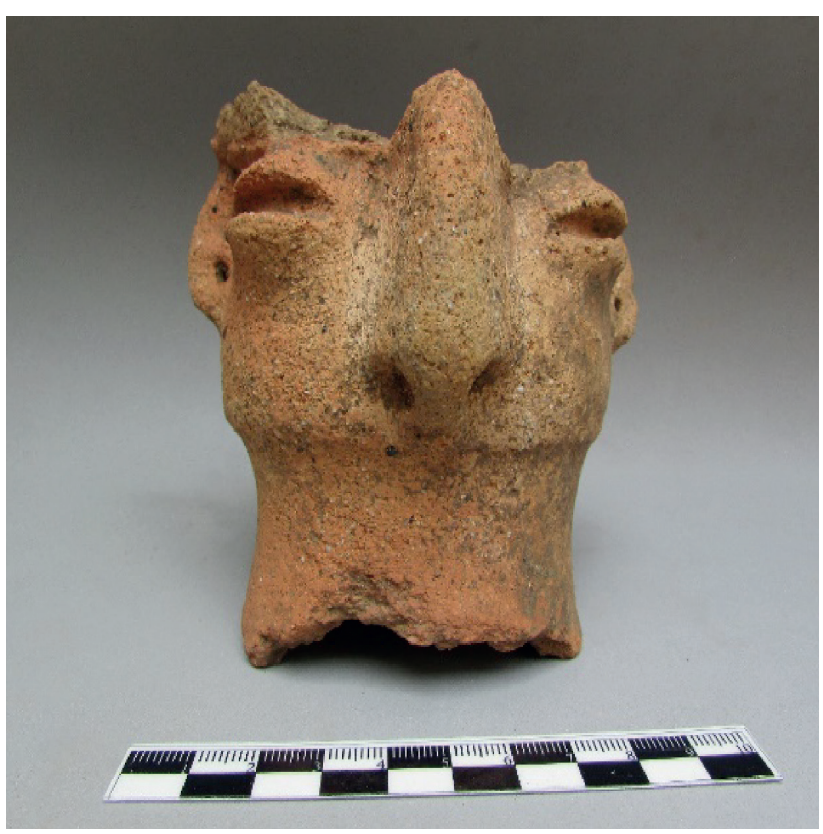

Figura antropomorfa fragmentada hallada en Macumba.

menores a $10 \mathrm{ppm}$ se consideran muy bajos, entre 10 y 20 ppm son bajos, entre 20 y 40 ppm son medios y mayores a $40 \mathrm{ppm}$ son altos, como es la situación que se presenta en las muestras aquí estudiadas (Castro y Gómez, 2010).

Los principales vestigios obtenidos fueron los siguientes: urnas funerarias, algunas con tapas, con y sin ajuares funerarios, tanto internos como externos; entre los cuales se destacan pequeñas vasijas globulares y subglobular tanto medianas como pequeñas, cuencos y copas, algunas de las vasijas presentaron tapas, en ocasiones se presentan decoraciones, figuras antropomorfas, cuentas de collar, copas, volantes de huso, herramientas líticas como hachas pulidas, metates y manos de moler.

En términos generales, tanto las urnas como los ajuares presentan características de una cerámica roja asociada a un contexto funerario. Los atributos de este tipo cerámico son: desgrasante con textura granulosa-porosa, se observan betas carbonizadas, sin embargo, algunas no presentan núcleo diferenciable, se hallan inclusiones de cuarzo molido con presencia de feldespato, mica en tamańos pequeńos y medianos con algunas excepciones de grandes incrustaciones. La pasta es de arena fina y semi- compacta.

En cuanto a la superficie el color es Rojo con múltiples tonalidades [HUE 2.5 YR, y 5 YR, Marrón fuerte], de textura lisa, y paredes generalmente homogéneas. La elaboración presenta un enrollado en 


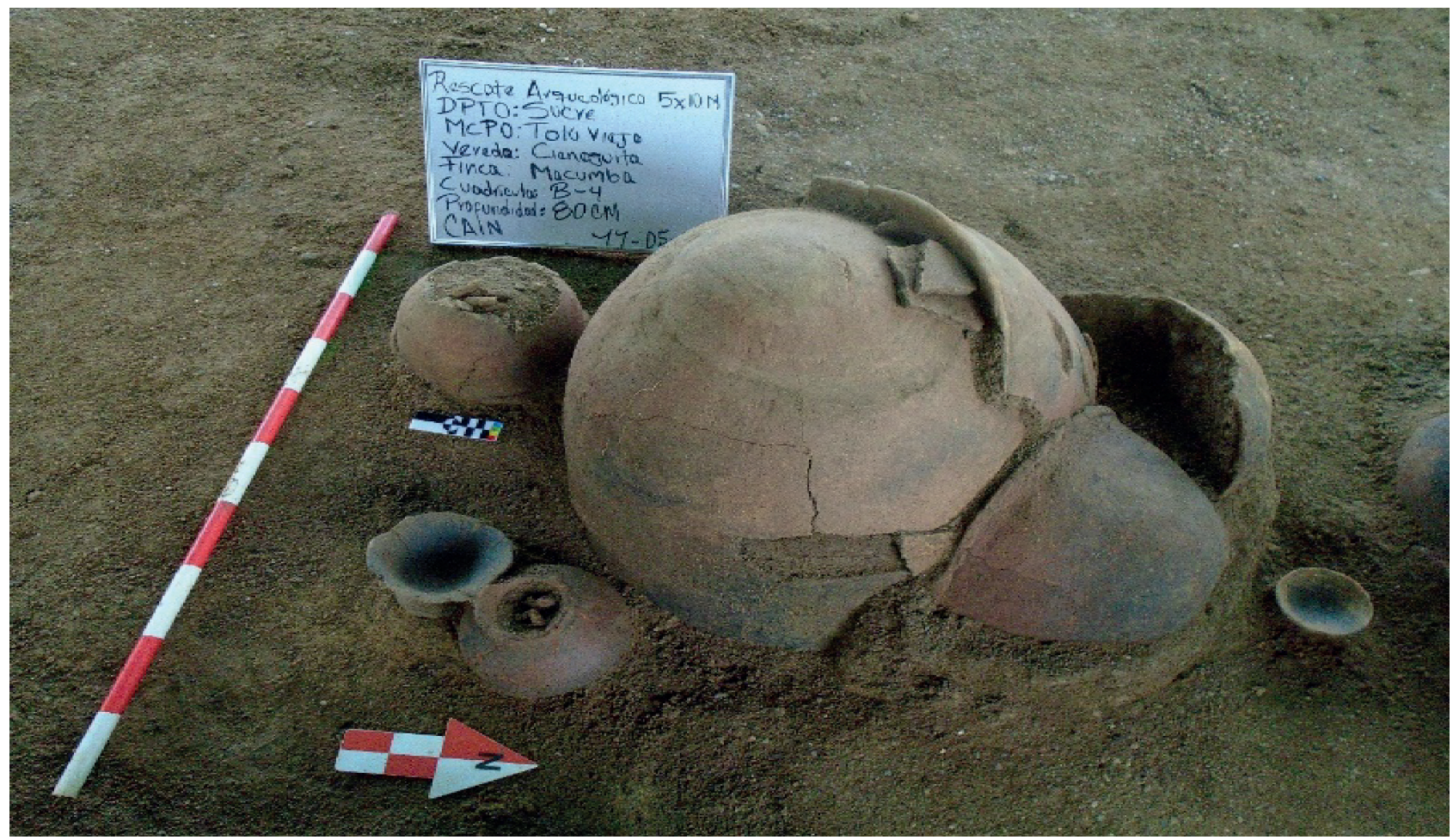

Detalle de excavación Macumba

espiral. Se hace presente la decoración de líneas incisas verticales y horizontales, excisiones, decoración de pequeños triángulos, aplicación de huellas dactilares y excisiones con triangulitos y moldeados. El material diagnóstico lo conforman bordes rectos reforzados y sin reforzar, evertidos con y sin refuerzo, invertidos, fragmentos de bases, fragmentos de labios, fragmentos de cuerpos decorados, algunos de los bordes (rectos, evertidos e invertidos) presentan decoraciones. Se tienen también elementos completos (copas, cuencos, ollas y vasijas).

Las actividades de análisis del material hallado realizadas en el laboratorio permitieron relacionarlo con fases tardías de la cerámica del Bajo Magdalena, donde se destaca la escasa diversidad estilística de los materiales. Los elementos líticos recuperados también están asociados a este tipo de ocupaciones tardías. Estos planteamientos estarían sustentando la posición inicial de que los grupos humanos que elaboraron esta cerámica estaban estrechamente relacionados con comunidades provenientes del rio Magdalena. Dichos grupos se encontraban organizados en pequeñas aldeas con casas dispersas y aprovechaban las estaciones para definir su movilidad. Para referenciar lo expuesto léase Reichel-Dolmatoff en su investigación en la zona de Zambrano (Reichel-Dolmatoff, 1991).
La presencia de restos óseos y dentales al interior de las urnas fue una constante. Su tratamiento consistió en el lavado de cada uno de los elementos, secado a temperatura ambiente y pegado con UHU en los casos en los que fue posible reconstruir, al menos parcialmente, algún elemento.

Para el caso de los dientes, se estudiaron las características morfológicas de cada una de las estructuras con el fin de identificar las piezas presentes (incisivos, caninos, premolares, molares) y determinar su posición anatómica (superior, inferior, izquierdo, derecho). Posteriormente, utilizando una base de cera dental, se reconstruyeron las arcadas dentales de cada uno de los individuos, para proceder al inventario de las mismas siguiendo la nomenclatura dentaria internacional.

Las evidencias corresponden a 18 individuos. En algunos casos se hallan los restos de dos individuos contenidos en una sola urna, como se puede observar en la urna 4, que contiene dos adultos; la urna 7 con un adulto y un niño; la urna 10 con dos adultos, y la urna 58 con un adulto y un juvenil.

De acurdo con los registros encontrados en tres muestras de suelo obtenidas durante la excavación del sitio arqueológico y luego del análisis paleoambiental, se observa un predominio de fitolitos tipo Globulolita 
y de microfragmentos de carbón vegetal. Esta asociación sugiere que tal vez fueron aprovechado o manejado recursos frutales del medio como palmas. Los carbones podrían estar relacionados con el uso de vegetación leñosa (p. ej., fitolitos tipo Braquiolita) y los hongos nos sugieren la presencia de la materia orgánica, probablemente deriva de la asociación ecológica mencionada. También fue posible identificar indicadores del manejo o aprovechamiento de recursos frutales y follaje de palmas (Arecaceae), y otras herbáceas, como pastos nativos. Igualmente, se observan fitolitos comunes en la vegetación leñosa, como, por ejemplo: Braquiolita y Flabellulita.

Los fitolitos presentes en las palmas, seguramente nos indiquen que los sitios se pudieron haber aprovechado frutales como las palmas y pastos nativos. Por ejemplo, ningún grupo de plantas presta al hombre tantos y tan diversos servicios como las palmas (Galeano y Bernal 2010). De las 231 especies de palmas nativas conocidas hasta ahora en el territorio colombiano, 142 (el 61\%) presta algún tipo de uso. El más extendido es la construcción: 82 especies son utilizadas para este fin; principalmente, se emplean las hojas para techar y los tallos enteros o hendidos como postes o para paredes y pisos (Galeano y Bernal, 2010).

Según Galeano y Bernal (2010), el segundo uso en importancia, tienen que ver con la alimentación humana o animal: 69 especies producen algún tipo de alimento. Otra categoría de uso tiene que ver con la producción tecnológica, la cual abarca unas 63 especies de las cuales se obtienen utensilios, instrumentos, juguetes, artesanías, adornos muchas otras aplicaciones. Y, por último, 14 especies se emplean con fines medicinales, cosméticos o rituales (Galeano y Bernal, 2010).

Desde punto de vista de la geoquímica, las muestras presentaron muy bajos niveles de materia orgánica, lo cual está en concordancia con el clima cálido y seco de la zona de estudio que favorece la mineralización de la materia orgánica y evita que ésta se acumule en cantidades altas en el suelo. Y esta situación podría correlacionarse con la falta de bioindicadores lacustres o acuáticos, de donde se infiere que en los sitios arqueológicos Macumba, entre los ańos 650 y $765 \mathrm{AD}$ y en el sitio La Floresta, entre los ańos 1650 y 1805 AD probablemente se presentaron condiciones de clima seco, lo cual coincide con las tendencias en la curva de incremento en la curva de la concentración del $\mathrm{CO} 2$ (g) para esta parte del Holoceno tardío de Sucre.

\section{Consideraciones finales}

Los vestigios culturales obtenidos durante la investigación que nos ocupa permiten inferir que los antiguos pobladores de La Floresta y Macumba en el actual municipio de Tolú Viejo, departamento de Sucre, enterraban a sus muertos en sitios altos no inundables, cercanos a fuentes de agua; en urnas funerarias tanto individuales como compartidas, con ajuares funerarios tanto externos, como internos; tenían materias primas para la fabricación de tecnología lítica como chert, cuarzo, basalto; utilizaron arcilla de color rojiza y/o negro y posiblemente realizaron intercambio con comunidades cercanas al Bajo Magdalena.

Los materiales líticos fueron en principio utilizados en las diferentes actividades agrícolas típicas de la comunidad $y$, posteriormente, se convirtieron, probablemente, en ajuares, en piezas que más tarde fueron enterradas con el individuo, la lítica pulida parece haber tenido un uso tal vez anterior al ritual funerario, del cual dan cuenta la presencia de astillamientos múltiples en el extremo distal de las hachas y cuñas para enmangar.

Para la realización de los enterramientos secundarios en La Floresta muy probablemente se llevó a cabo una primera nivelación del área para la disposición del material cultural. Dicha nivelación pudo haberse realizado en épocas de lluvia, al finalizar el período seco en la Costa Caribe colombiana (entre los meses de octubre y diciembre), donde el suelo pudo consolidarse con características friables, lo que permitiría su intervención, pues se trata de un suelo muy compacto en tiempo seco, muy difícil de excavar.

En Macumba, por el contario, esta no puede apreciarse tal nivelación: las urnas se encuentran en diferentes niveles y en oportunidades asociadas a vasijas ovaladas con tapa con decoración de impresiones dactilares en su borde externo, debajo de la cual se hallaba otra vasija de forma globular en la que reposaban restos óseos característicos de la etnia Malibú. Las urnas también presentaban ajuares funerarios, compuestos por copas, cuencos uno encima del otro, dando el aspecto de un cofre circular, y vasijas boca abajo. Este tipo de urnas son muy similares a las halladas en las excavaciones en el municipio de Los Palmitos, departamento de Sucre (Choperena, 2015).

El $60.4 \%$ de los individuos enterrados en Macumba y La Floresta eran mayores de los 20 ańos, el 14.6\% eran individuos de 12 a 20 años y, por último, se 
tiene un $25 \%$ correspondiente a niños. Se presentaron entierros de 1, 2 y hasta 3 individuos por urna, sin distinción de edad ni sexo.

Así las cosas, el área de influencia directa del proyecto en el municipio de Tolú Viejo, podría ser un lugar de convergencia cultural que mostraría una vez más la dinámica social de los grupos humanos en épocas prehispánicas, haciendo con ello difusa la delimitación fronteriza entre ellos, particularmente entre los Malibú y Zenú que ocuparon el corredor del proyecto. Sin embargo, estos planteamientos deben ser corroborados en futuras investigaciones.

\section{Referencias bibliográficas}

Archila, Sonia (1993). «Medio ambiente y arqueología en las tierras bajas del Caribe Colombiano», en Boletín del Museo del Oro, n. ${ }^{\circ}$ 34-35. Bogotá: Banco de la República..

Briones, De Pedraza (1983). «Relación de la Villa de Tenerife», en Revista Cespedesia. Suplemento, 4, Cali, Colombia.

Castro, H.E y Gómez, M.I. (2010). «Fertilidad de suelos y fertilizantes», en Ciencia del suelo: principios básicos. Colombia, editorial: Sociedad Colombiana de la Ciencia del Suelo. 213-303 p. Bogotá, Colombia.

Chacín, Regina (1999). Dimensionamiento arqueológico del sitio K2+050 del gasoducto Ayombe-Guepajé-1. Departamento de Sucre, municipio de San Pedro. Petrobrás Colombia Ltda. Bogotá. (S.P).

Chacín, Regina (2005). Prospección arqueológica para el Programa Sísmico La Creciente 2005. Stratus Oil \& Gas. Bogotá. (S.P).

Choperena, Luis Carlos (2015). Informe final. Proceso de laboratorio arqueológico para las evidencias obtenidas durante las excavaciones en el Yacimiento San Felipe, Los Palmitos (Sucre). Fundación de Investigaciones Arqueológicas Nacionales. Banco de la República. Proyecto 455. Bogotá, Colombia.

ICANH (2010). Régimen legal y lineamientos técnicos de los Programas de Arqueología Preventiva en Colombia. Versión Pdf. 2010, Bogotá, Colombia.

Escalante, Aquiles (1955). «Los Mocaná», en Divulgaciones etnológicas: Universidad del Atlántico, 1955. Vol. 4, No 6, p. 5-115. Barranquilla, Colombia.

Falchetti, Ana María (1979). «Colgantes Darién: relaciones entre áreas orfebrería del occidente colombiano y Centroamérica», en Boletín del Museo del Oro, año 2, Bogotá, Colombia.
Falchetti, Ana María (1995a). «La tierra del oro y el cobre: parentesco e intercambio entre comunidades orfebres del norte de Colombia y áreas relacionadas», en Boletín del Museo del Oro, No 34-35: pp. 03 - 204, Bogotá, Colombia.

Falchetti, Ana María (1995b). El oro del Gran Zenú. Metalurgia prehispánica en las llanuras del Caribe colombiano. Banco de la República, Bogotá, Colombia.

Falchetti, Ana María (1996). «El territorio del Gran Zenú, en las llanuras del Caribe Colombiano: Arqueología y Etnohistoria», en Revista de Arqueología Americana, Instituto Panamericano de Geografía e Historia, No 11. Julio-diciembre: pp. 7-41.

Falchetti, Ana María (1999). «El poder simbólico de los metales: la tumbaga y las transformaciones metalúrgicas», en Boletín de Arqueología, FIAN, Año 14 No 02: pp. 5382. Bogotá, Colombia.

Falchetti, Ana María (2010). El ocaso del Gran Zenú en Cartagena de Indias en el siglo XVI, Haroldo Calvo y Adolfo Meisel editores. Banco de la República, Cartagena, Colombia.

Galeano, G \& R. Bernal (2010). Palmas de Colombia. Instituto de Ciencias Naturales Universidad Nacional de Colombia. Editorial Universidad Nacional de Colombia. 688 pp. Bogotá, Colombia.

Langebaek, Carl Henrik; Cuellar, Andrea y Dever, Alejandro (1997). «Medio Ambiente y Poblamiento en la Guajira. Investigaciones Arqueológicas en el Ranchería Medio", es Estudios Antropológicos No. 1. Universidad de los Andes, Departamento de Antropología, 115 p. Bogotá, Colombia.

Langebaek, Carl Henrik, Dever, Alejandro (2000). «Arqueología en el Bajo Magdalena. Un estudio de los primeros agricultores del Caribe colombiano». Informes Arqueológicos del ICANH. Bogotá, Colombia. (S.P).

Langebaek, Carl Henrik y Dever Alexandro (2000). «Arqueología en el Bajo Magdalena: un estudio de los primeros agricultores del Caribe colombiano", en Informes Arqueológicos del Instituto Colombiano de Antropología e Historia №1. Bogotá, Colombia.

Lozada Mendieta, Natalia (2013). «Aportes recientes a la discusión sobre las ocupaciones prehispánicas en el Caribe colombiano: la cerámica de los sitios San Isidro y Cacaramoa (Sabanagrande, Atlántico)», en Anales de 25 Congreso IACA-AIAC, Puerto Rico.

Oviedo y Valdés (1535). Historia General de las Indias. Tomo 1, Juan Cromberger, Sevilla, España.

Oleoducto de Colombia, S.A, ICANH, ECOPETROL (1994). Arqueología de rescate. Oleoducto Vasconia- 
Coveñas: un viaje por el tiempo a lo largo del oleoducto; cazadores-recolectores, agro alfareros y orfebres. Editora Guadalupe Ltda. Bogotá, Colombia.

Ortiz Guerrero, C., M. E. Pérez Martínez y I. A. MuÑoz Wilches (2006). Los cambios institucionales y el conflicto ambiental. El caso de los valles del río Sinú y San Jorge. Editorial Pontificia Universidad Javeriana. Bogotá, Colombia.

Oyuela, Augusto (1995). Rocks versus Clay: The Evolution of Pottery Technology in the case of San Jacinto 1. In: The emergence of Pottery - Technology and Innovation in Ancient Societies. Eds. W. Barnett \& J. Hoopes. Smithsonian Institution Press. Washington.

Plazas, Clemencia y Falchetti, Ana María (1981). Asentamientos prehispánicos en el bajo río San Jorge. Bogotá: Fundación de Investigaciones Arqueológicas Nacionales, Banco de la República. Bogotá, Colombia.

Plazas, Clemencia; Falchetti, Ana María; Saenz, Juanita y Archila, Sonia (1993). La sociedad hidráulica Zenú. Banco de la República, Bogotá, Colombia

PROMIGAS, Corporación Antropológica para la Investigación CAIN (2017). Informe final Programa de Arqueología Preventiva. Rescate, divulgación (Arqueología pública) y monitoreo arqueológico. Gasoducto Loop san Mateo - Mamonal. Barranquilla, Colombia. (S.P).

Reichel-Dolmatoff, Gerardo (1982). Cultural change and environmental awareness: a case study of the Sierra Nevada de Santa Marta, Colombia. Mountain Research and Development, 2(3): 289-298.

Reichel-Dolmatoff, Gerardo y Dolmatoff Alicia (1991). Arqueología del Bajo Magdalena. Estudio de la cerámica de
Zambrano. Colección Textos Universitarios. Biblioteca Banco Popular. Colcultura. ICAN. Bogotá, Colombia.

Reichel-Dolmatoff, Gerardo (1986). Arqueología de Colombia: un texto introductorio. Segunda Expedición Botánica. Bogotá, Colombia.

Reichel-Dolmatoff, Gerardo (1954). «Contribuciones a la arqueología del Bajo Magdalena: Plato, Zambrano, Tenerife», en Divulgaciones Etnológicas, Vol. 3, No. 5, junio. Universidad del Atlántico - Instituto de Investigaciones Etnológicas. Barranquilla, Colombia.

Rodríguez, Camilo (1999). Cacicazgos precolombinos y fronteras étnicas: El caso de la tradición Malambo y los Chimila del Bajo río Magdalena. Estudio arqueológico para la línea de transmisión Sabanalarga - Fundación. Colombia siglo XXI. (S.P).

Rodríguez, Camilo (1988). «Las tradiciones alfareras tempranas en el Caribe Colombiano (Departamento de Bolívar y Atlántico). Periodización y comparación cerámica». Boletín de Arqueología Fundación de Investigaciones Arqueológicas nacionales FIAN. Bogotá, Colombia.

Serna Ramírez, Aceneth. Oleoducto Bicentenario de Colombia-ERM-CAIN (2012). Medioambiente y asentamientos prehispánicos en el Caribe colombiano. Prospección arqueológica preventiva Oleoducto Bicentenario de Colombia. Tramo Ayacucho - Coveñas. Informe Final. Bogotá. (S.P).

www.sahaguncordoba.com_en línea con mi pueblo_los zenú. (Fecha de consulta: 13 de noviembre de 2017). 